\title{
Female Genital Mutilation Helpline
}

\section{Susan Quilliam}

Writer, Broadcaster, Consultant and Trainer, Cambridge, UK

Correspondence to Ms Susan Quilliam, Cambridge, UK; susan@susanquilliam.com; http://www.susanquilliam.com

Received 9 February 2014 Accepted 9 February 2014
To cite: Quilliam S. J Fam Plann Reprod Health Care 2014;40:145-147.

\section{WHAT IS THE FGM HELPLINE?}

We at the National Society for the Prevention of Cruelty to Children (NSPCC) have launched a new helpline to protect children in Britain from female genital mutilation (FGM).

\section{WHAT IS FGM?}

FGM is an initiation ritual common to some African, Asian and Middle Eastern communities worldwide. Carried out in secret and often without anaesthetic, it involves the partial or total removal of the external female genital organs; victims are usually aged between 4 and 10 years, but some are babies. As well as being painful and often life-threatening, the procedure can leave girls with physical and psychological problems that continue into adulthood and affect sexual activity and childbearing. The practice of FGM is a form of abuse and is illegal in Britain.

\section{HOW BIG IS THE NEED?}

Every month more than 70 women and girls seek treatment in Britain, with over 1700 referred to specialist clinics from 2011 to 2013. However, we believe the true number of victims is even higher only a tiny fraction of those affected come forward for medical help, usually because of maternity problems.

\section{WHY A HELPLINE?}

Children who are at risk and women who have suffered FGM often do not know the practice is harmful and abusive. They are told by their family that being cut is in their best interest, and that if they are not cut, they are unclean and immoral. There is also huge pressure within communities to keep quiet about FGM; some people are even threatened with violence if they speak out.

We believe a dedicated helpline, with specially-trained child protection advisors, will help inform sufferers, break the silence and allow those affected and at risk to come forward.

\section{WHO IS THE HELPLINE FOR?}

Anyone concerned that a child's welfare is at risk can speak to us: a girl, her family, a community member or health professionals such as Journal readers. We offer information, advice and support.

\section{IS THE HELPLINE CONFIDENTIAL?}

Yes. We want this helpline to be a safe space that anyone can use without fear of reprisal. So callers' details can remain anonymous, though any information that could protect a child from abuse will be passed to the police or social services.

\section{WHO MANS THE HELPLINE?}

We have a team of child protection advisors who have received training and advice from two organisations, Equality Now (http://www.equalitynow.org/ourwork) and Daughters of Eve (http://www.dofeve.org/) that specialise in protecting female rights, in particular around FGM.

\section{WHY DO JOURNAL READERS NEED TO KNOW ABOUT THE FGM HELPLINE?}

The recent Intercollegiate Report on FGM (Box 1) clearly states that frontline health professionals have an accountable duty of care. In a statement ${ }^{1}$ made in Summer 2013, the Royal College of Obstetricians and Gynaecologists also said: "It is the duty of doctors, nurses, midwives and health visitors to identify the girls whom they believe are at risk and to share such information in good faith with the local safeguarding networks so these girls can be monitored and protected by social services". The same level of duty of care applies when women who have already suffered FGM present for treatment and support.

We believe that health professionals such as readers of this Journal are especially important in helping to protect children from FGM and in referring patients for specialist treatment if FGM has happened. Many general practitioners will be on the front line if families wish to protect their daughters, while many 
In November 2013, a coalition of Royal Colleges, trade unions and Equality Now launched the report Tackling FGM in the UK: Intercollegiate Recommendations for Identifying, Recording and Reporting. ${ }^{2}$ The report makes the following nine recommendations:

1 Treat it as child abuse: Female genital mutilation (FGM) is a severe form of violence against women and girls. It is child abuse and must be integrated into all UK child safeguarding procedures in a systematic way.

2 Document and collect information: The National Health Service (NHS) should document and collect information on FGM and its associated complications in a consistent and rigorous way.

3 Share that information systematically: The NHS should develop protocols for sharing information about girls at risk of - or girls who have already undergone - FGM with other health and social care agencies, the Department for Education and the police.

4 Empower frontline professionals: Develop the competence, knowledge and awareness of frontline health professionals to ensure prevention and protection of girls at risk of FGM. Also ensure that health professionals know how to provide quality care for girls and women who suffer complications of FGM.

5 Identify girls at risk and refer them as part of child safeguarding obligation: Health professionals should identify girls at risk of FGM as early as possible. All suspected cases should be referred as part of existing child safeguarding obligations. Sustained information and support should be given to families to protect girls at risk.

6 Report cases of FGM: All girls and women presenting with FGM within the NHS must be considered as potential victims of crime, and should be referred to the police and support services.

7 Hold frontline professionals accountable: The NHS and local authorities should systematically measure the performance of frontline health professionals against agreed standards for addressing FGM and publish outcomes to monitor the progress of implementing these recommendations.

8 Empower and support affected girls and young women (both those at risk and survivors): This should be a priority public health consideration; health and education professionals should work together to integrate FGM into prevention messages [especially those focused on avoiding harm, e.g. National Society for the Prevention of Cruelty to Children (NSPCC) 'Pants' Campaign, Personal, Social and Health Education, extracurricular activities for young people].

9 Implement awareness campaign: The government should implement a national public health and legal awareness publicity campaign on FGM, similar to previous domestic abuse and HIV campaigns.

Journal readers may also wish to refer to an RCOG commentary ${ }^{3}$ on the report, from which this summary is taken, and which also suggests further reference websites.

family planning, maternity and fertility professionals will see the consequences of FGM first-hand when women come with resulting problems.

\section{WHAT DANGER SIGNS SHOULD ONE LOOK OUT FOR?}

In terms of potential FGM, one should be alert if a girl is from a community where FGM is practised, particularly if a member of her family has already suffered the procedure. In particular, although FGM can be carried out on British soil, it may be a danger sign if a girl from such a community presents for immunisations for a trip abroad over the summer holiday.

In terms of a patient having undergone FGM, the British Medical Association lists the following danger signs: difficulty walking, sitting or standing; longer than normal time in the bathroom or toilet due to difficulties urinating; frequent urinary or menstrual problems; a reluctance to undergo normal medical examinations, for example, cervical smears.

\section{WHAT SHOULD ONE DO IF ONE SUSPECTS A PATIENT IS POTENTIALLY ABOUT TO UNDERGO FGM?}

We would recommend having an honest conversation about these concerns with the child's parents. Explain that it is illegal to have the girl cut, and set out the health consequences, including the fact that she may suffer unimaginable pain; later difficulties in sexual activity, menstruation, conception and childbearing; and possible death.

If there is any doubt about a child's safety, or if the professional believes FGM has already taken place, concerns should be reported to the police and children's services so they can investigate and protect the girl.

\section{WHAT SUPPORT CAN ONE OFFER TO CLIENTS WHO ARE AGAINST THEIR DAUGHTERS SUFFERING FGM?}

Within FGM practising communities there can be a lot of pressure on parents to subject their daughter to 
FGM. Many people are not aware that FGM is illegal in Britain, and if one can explain that this is the case whether the procedure happens in this country or abroad, parents may feel more able to resist pressure.

\section{WHAT SUPPORT CAN ONE OFFER TO CLIENTS WHO HAVE SUFFERED FGM?}

There are specialist clinics that can treat some of the medical problems caused by FGM, and specialist counsellors who can offer support for the serious psychological damage that can follow the procedure. Health professionals can guide patients towards these specialists; for further information, contact the Helpline (details below).

\section{WHAT IS YOUR PLEA TO JOURNAL READERS?}

Please watch for evidence that patients have suffered, or are about to suffer FGM. Please let all patients know about the helpline. Please spread the word among your colleagues. Please help us to stop the abuse.

\section{HELPLINE DETAILS}

The FGM Helpline is for anyone, client or professional, who is concerned that a child's welfare is at risk because of FGM. It is free, 24-hour, confidential and anonymous: the number (if calling in the UK) is 08000283550 .
For clinic waiting area posters call the NSPCC on 08088005000 or e-mail help@nspcc.org.uk.

\section{Competing interests None.}

Provenance and peer review Commissioned; internally peer reviewed.

Editor's note This article is one in a series of occasional articles on key health organisations worldwide. The Journal would be pleased to hear from other organisations, particularly those based outside the UK, which would like to be similarly profiled.

\section{REFERENCES}

1 Royal College of Obstetricians and Gynaecologists. RCOG statement on the UNICEF report on FGM trends. 2013. http:// www.rcog.org.uk/news/rcog-statement-unicef-report-fgm-trends [accessed 28 January 2014].

2 Royal College of Obstetricians and Gynaecologists, Royal College of Nursing, The Royal College of Midwives, Equality Now, UNITE. Tackling FGM in the UK: Intercollegiate Recommendations for Identifying, Recording and Reporting. 2013. http://www.rcog.org.uk/files/rcog-corp/FGM_Report\% 20v10\%20a final\%20forwebsite.pdf [accessed 28 January 2014].

3 Royal College of Obstetricians and Gynaecologists. Intercollegiate Group draws up ground-breaking recommendations for tackling Female Genital Mutilation. 2013. http://www.rcog.org.uk/news/intercollegiate-group-drawsground-breaking-recommendations-tackling-female-genitalmutilation [accessed 28 January 2014]. 